\title{
Boosting electrocatalytic HER activity of 3D interconnected CoSP via metal doping: Active and stable electrocatalyst for pH-universal Hydrogen
}

\section{Generation}

Viet Q. Bui, ${ }^{\dagger}, \#$ Ashwani Kumar, ${ }^{\dagger}, \#$ Huong T. D. Bui, M. Le, ${ }^{\S}$ Yoshiyuki Kawazoe, and Hyoyoung Lee ${ }^{* \dagger, t, \bar{\top}}$

${ }^{\dagger}$ Center for Integrated Nanostructure Physics (CINAP), Institute for Basic Science (IBS), Sungkyunkwan University, Suwon 16419, Korea

¥Department of Chemistry, Sungkyunkwan University (SKKU), Suwon, 16419, Republic of Korea

${ }^{\bar{T}}$ Department of Biophysics, Sungkyunkwan University (SKKU), Suwon, 16419, Republic of Korea

$\S$ Department of Chemistry, Washington State University, Pullman, WA 99164

"New Industry Creation Hatchery Center, Tohoku University, Sendai, 980-8579, Japan

*Email of correspondence: hyoyoung@skku.edu

\# Both authors contributed equally to this work 


\section{This document includes:}

Figure S1: The favorable configurations of metal single atom adsorbed on CoSP structure.

Figure S2: The charge density difference of catalyst surface.

Table S1: Corrections with free energy formation of $\mathrm{H}^{*}$ desorption on catalytic surfaces.

Figure S3: Gibbs free energy diagrams for $\mathrm{H}$ adsorption on TM-CoSP catalysts.

Table S2: Details for the $\mathrm{H}_{2} \mathrm{O}$ molecule adsorbed on catalytic surfaces.

Figure S4: Reaction pathway of first water dissociation on catalytic surfaces.

Figure S5: Reaction pathways of the second step on catalytic surfaces.

Figure S6: Gibbs free energy diagrams of HER in alkaline condition.

Figure S7: X-ray diffraction (XRD) pattern; field-emission scanning electron microscopy (FESEM) image.

Figure S8: FESEM images.

Table S3: Atomic \% of different elements and the molar ratio of S/P obtained from EDAX, averaged over multiple locations.

Figure S9: Energy-dispersive X-ray spectroscopy (EDS) pattern.

Figure S10: HRTEM images.

Figure S11: The overpotentials required to reach a high current density of -50 and $-100 \mathrm{~mA} \mathrm{~cm}{ }^{-2}$ for HER in acidic media

Table S4: Comparison table for the HER performance of catalyst in this work with other reported electrocatalysts.

Figure S12: The overpotentials required to reach a high current density of -50 and $-100 \mathrm{~mA} \mathrm{~cm}{ }^{-2}$ for HER in alkaline media.

Figure S13: Nyquist plots obtained by EIS.

Figure S14: Cyclic voltammetry (CV) plots.

Figure S15: Normalization of HER activity with respect to their corresponding the electrochemical active surface area (ECSA).

Figure S16: Long-term chronopotentiometric stability test.

Figure S17: PXRD patterns after the stability tests in acidic and alkaline media. FESEM images, EDS spectra, and EDS mapping after the stability test in acidic and alkaline media.

Figure S18: Reproducibility test of $\mathrm{Co}_{0.97} \mathrm{Ti}_{0.03} \mathrm{SP}$ for the HER. 

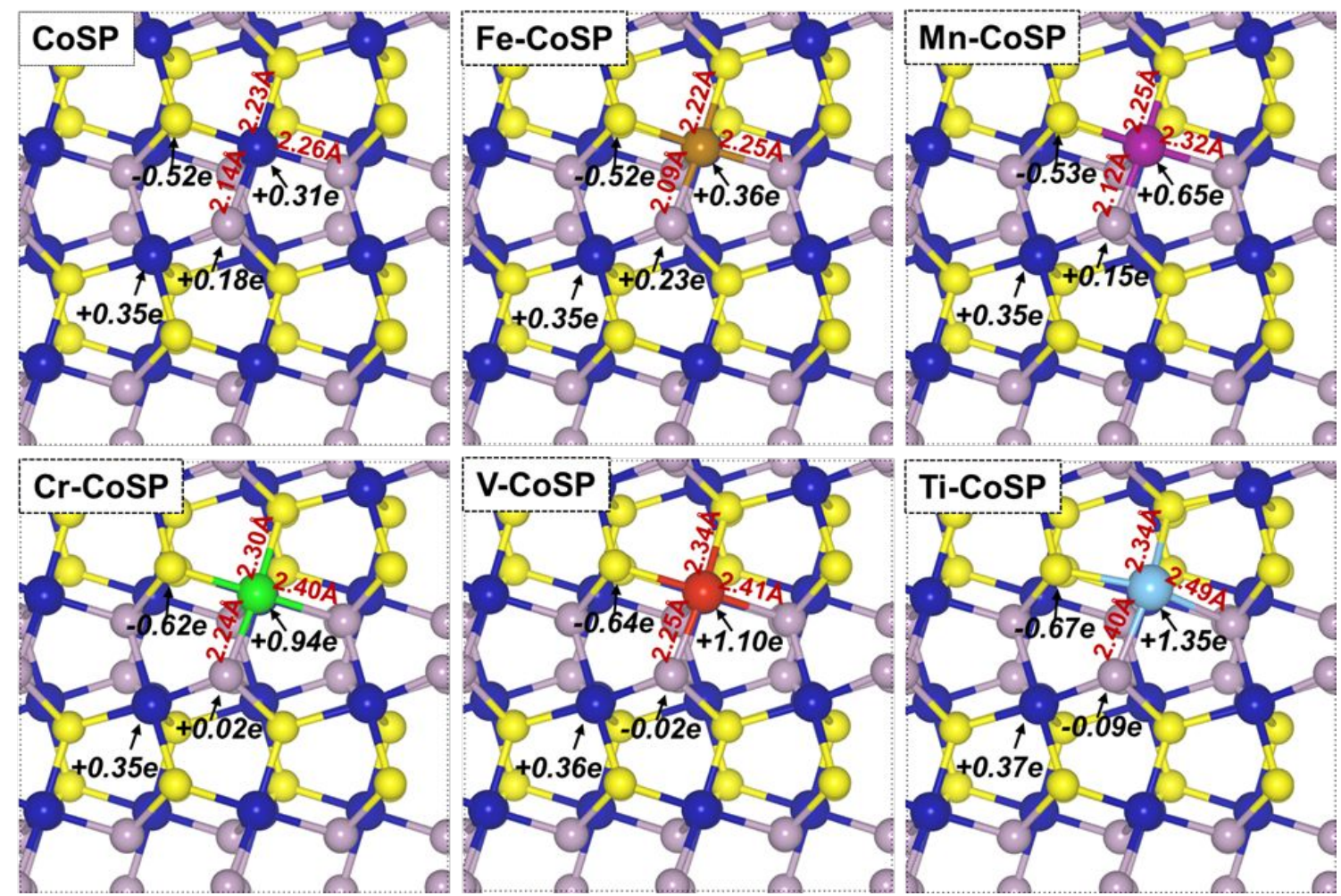

Figure S1. The favorable configurations of metal single atom adsorbed on CoSP structure, namely CoSP, Fe-CoSP, Cr-CoSP, Mn-CoSP, V-CoSP, and Ti-CoSP, respectively 

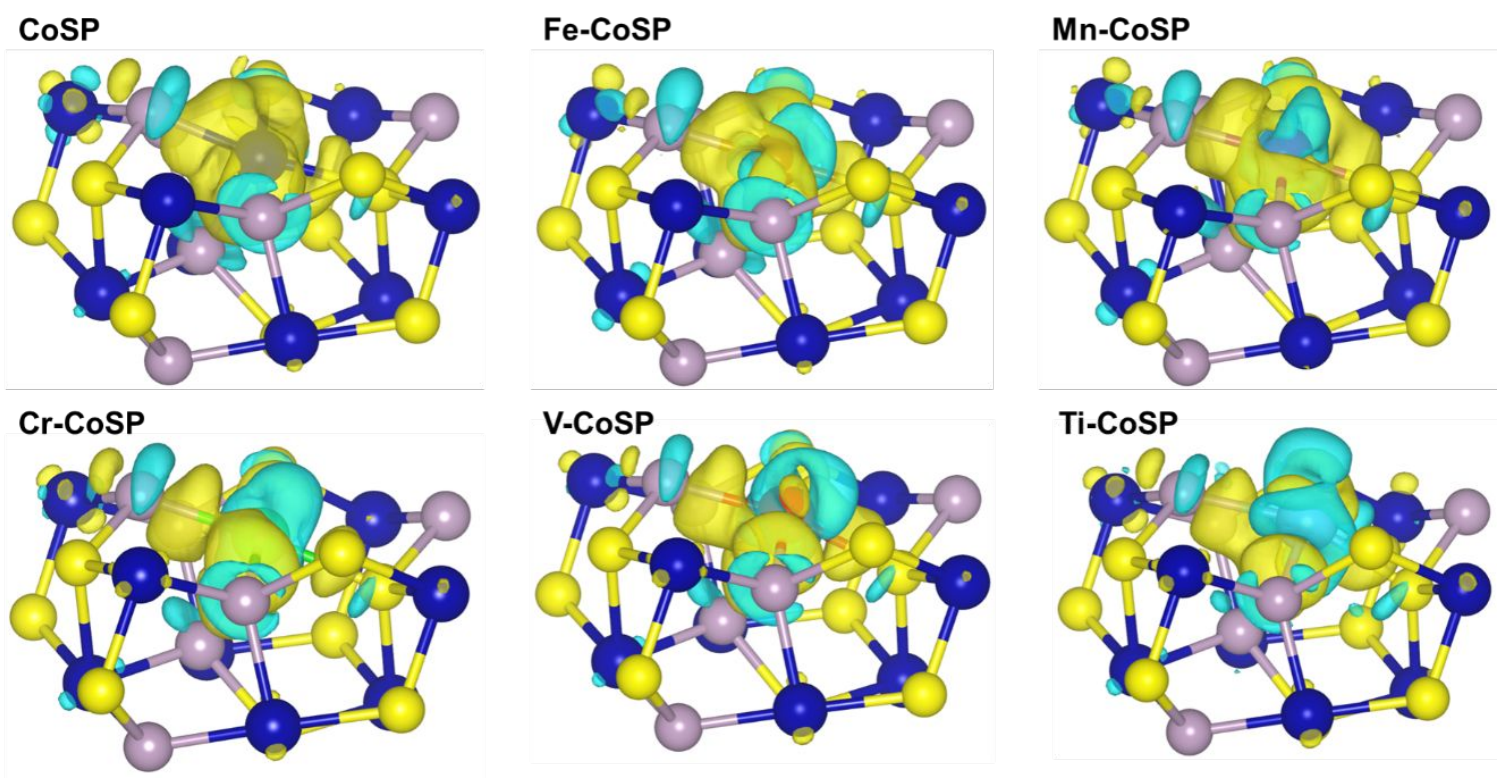

Figure S2. The charge density difference of catalyst surface. The yellow and cyan regions represent electron accumulation and depletion. The isosurface value is $0.0025 \mathrm{e} / \mathrm{bohr}^{3}$. The differential charge density is determined by the difference between the charge density of compound and individual components. $\Delta \rho=\rho_{\mathrm{TM}-\operatorname{CoSP}}-\rho_{\mathrm{CoSP}}-\rho_{\mathrm{TM}}$ 
Table S1: Corrections with free energy formation of $\mathrm{H}^{*}$ desorption on catalytic surfaces.

\begin{tabular}{|c|c|c|c|c|}
\hline \multicolumn{2}{|r|}{$\mathbf{H}^{*}$} & Adsorption energy (eV) & $\Delta \mathbf{E}_{\mathrm{ZPE}}-\mathrm{T} \Delta \mathrm{S}(\mathrm{eV})$ & $\Delta \mathbf{G}(\mathbf{e V})$ \\
\hline \multirow{4}{*}{ CoSP } & Co & 0.309 & 0.249 & 0.558 \\
\hline & $\mathrm{S}$ & 0.378 & 0.294 & 0.672 \\
\hline & $\mathrm{P}$ & -0.477 & 0.287 & -0.191 \\
\hline & Co (with $\mathrm{H}^{*}$ at $\mathrm{P}$ ) & -0.326 & 0.274 & -0.052 \\
\hline \multirow{5}{*}{ Fe-CoSP } & $\mathrm{Co}$ & -0.198 & 0.264 & 0.066 \\
\hline & $\mathrm{Fe}$ & 0.218 & 0.237 & 0.455 \\
\hline & $\mathrm{P}$ & -0.418 & 0.286 & -0.132 \\
\hline & $\mathrm{S}$ & 0.345 & 0.295 & 0.640 \\
\hline & Co (with $\mathrm{H}^{*}$ at $\mathrm{P}$ ) & -0.266 & 0.273 & 0.007 \\
\hline \multirow{5}{*}{ Mn-CoSP } & $\mathrm{Co}$ & -0.261 & 0.266 & 0.006 \\
\hline & $\mathrm{Mn}$ & 0.442 & 0.225 & 0.442 \\
\hline & $\mathrm{P}$ & -0.457 & 0.286 & -0.171 \\
\hline & $\mathrm{S}$ & 0.324 & 0.295 & 0.619 \\
\hline & Co (with $\mathrm{H}^{*}$ at $\left.\mathrm{P}\right)$ & -0.331 & 0.273 & -0.059 \\
\hline \multirow{5}{*}{ Cr-CoSP } & $\mathrm{Co}$ & 0.011 & 0.263 & 0.274 \\
\hline & $\mathrm{Cr}$ & 0.370 & 0.230 & 0.600 \\
\hline & $\mathrm{P}$ & -0.523 & 0.287 & -0.236 \\
\hline & $\mathrm{S}$ & 0.394 & 0.295 & 0.688 \\
\hline & Co (with $\mathrm{H}^{*}$ at $\left.\mathrm{P}\right)$ & -0.335 & 0.273 & -0.063 \\
\hline \multirow{5}{*}{ V-CoSP } & Co & -0.235 & 0.267 & 0.032 \\
\hline & $\mathrm{V}$ & 0.073 & 0.241 & 0.315 \\
\hline & $\mathrm{P}$ & -0.476 & 0.286 & -0.189 \\
\hline & $\mathrm{S}$ & 0.370 & 0.291 & 0.661 \\
\hline & Co (with $\mathrm{H}^{*}$ at $\mathrm{P}$ ) & -0.330 & 0.273 & -0.056 \\
\hline \multirow{5}{*}{ Ti-CoSP } & $\mathrm{Co}$ & -0.196 & 0.267 & 0.071 \\
\hline & $\mathrm{Ti}$ & 0.333 & 0.217 & 0.551 \\
\hline & $\mathrm{P}$ & -0.361 & 0.281 & -0.081 \\
\hline & $\mathrm{S}$ & 0.470 & 0.292 & 0.761 \\
\hline & $\mathrm{Co}\left(\right.$ with $\mathrm{H}^{*}$ at $\left.\mathrm{P}\right)$ & -0.320 & 0.275 & -0.045 \\
\hline
\end{tabular}




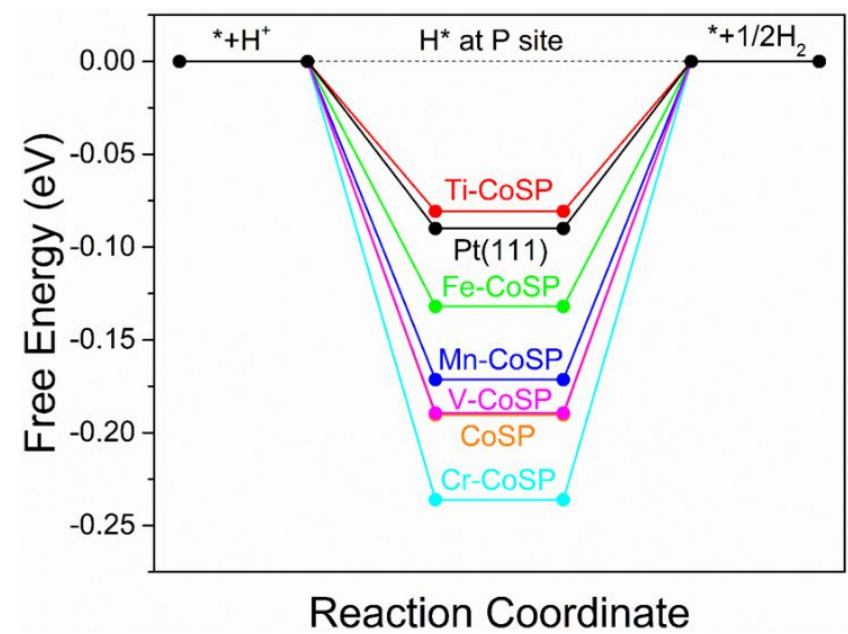

Figure S3. Gibbs free energy diagrams for $\mathrm{H}$ adsorption on TM-CoSP catalysts. 
Table S2. Details for the $\mathrm{H}_{2} \mathrm{O}$ molecule adsorbed on the catalysts. Herein, $\mathrm{d}_{\mathrm{O}-\mathrm{M}}$ is distance between the $\mathrm{O}$ and metal doping, $\mathrm{d}_{\mathrm{O}-\mathrm{H}}$ is the distance between $\mathrm{O}$ and $\mathrm{H}$; Phi $(\mathrm{H}-\mathrm{O}-\mathrm{H})$ is the angle of the first $\mathrm{H}_{2} \mathrm{O} ; \mathrm{E}_{\text {ads }}\left(\mathrm{H}_{2} \mathrm{O}^{1}\right)$ and $\mathrm{E}_{\text {ads }}\left(\mathrm{H}_{2} \mathrm{O}^{2}\right)$ are the adsorption energy of first and second $\mathrm{H}_{2} \mathrm{O}$, respectively.

\begin{tabular}{lccccc}
\hline & $\mathrm{d}_{\mathrm{O}-\mathrm{M}}(\AA)$ & $\mathrm{d}_{\mathrm{O}-\mathrm{H}}(\AA)$ & $\mathrm{Phi}(\mathrm{H}-\mathrm{O}-\mathrm{H})$ & $\mathrm{E}_{\mathrm{ads}}\left(\mathrm{H}_{2} \mathrm{O}^{1}\right)(\mathrm{eV})$ & $\mathrm{E}_{\text {ads }}\left(\mathrm{H}_{2} \mathrm{O}^{2}\right) \mathrm{eV}$ \\
\hline Free $\mathrm{H}_{2} \mathrm{O}$ & - & 0.973 & 104.46 & - & \\
CoSP & 2.16 & 0.976 & 106.49 & -0.51 & -0.55 \\
$\mathrm{Fe}-\mathrm{CoSP}$ & 2.18 & 0.975 & 106.81 & -0.53 & -1.12 \\
$\mathrm{Cr}-\mathrm{CoSP}$ & 2.16 & 0.975 & 107.39 & -0.83 & -0.77 \\
$\mathrm{Mn}-\mathrm{CoSP}$ & 2.13 & 0.974 & 107.07 & -0.72 & -0.67 \\
Ti-CoSP & 2.15 & 0.976 & 107.32 & -1.07 & -0.82 \\
V-CoSP & 2.12 & 0.975 & 108.09 & -1.00 & -1.09 \\
\hline
\end{tabular}




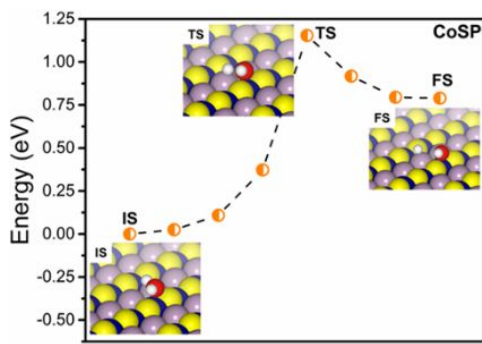

Reaction coordinate

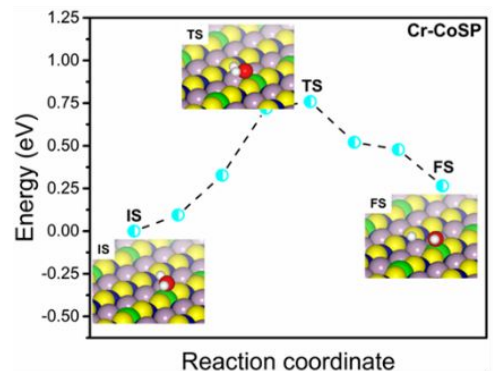

Reaction coordinate
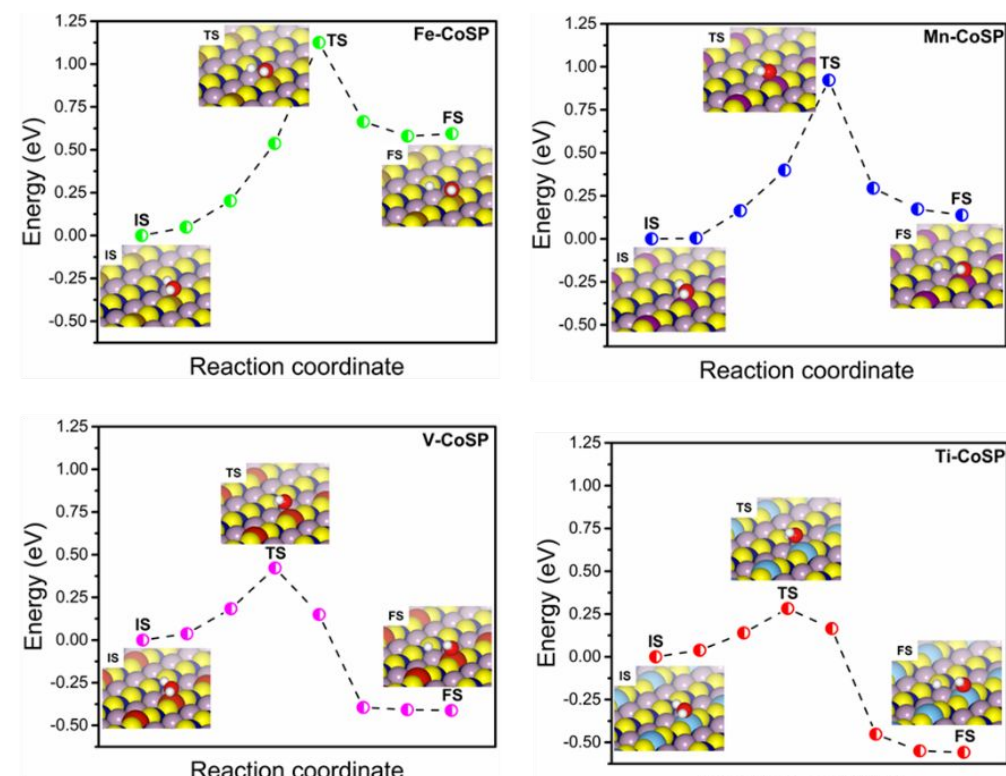

Reaction coordinate

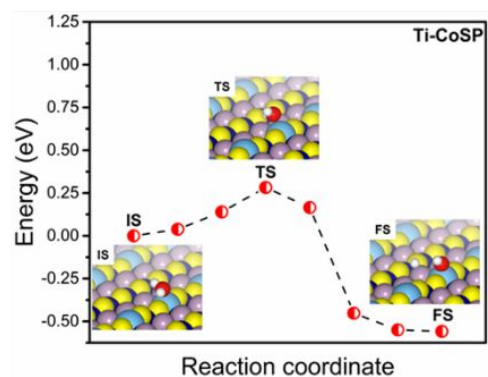

Figure S4. Determined reaction pathway of first water dissociation via Heyrovsky reaction; insets depict configurations of initial, transition states, and final states. 

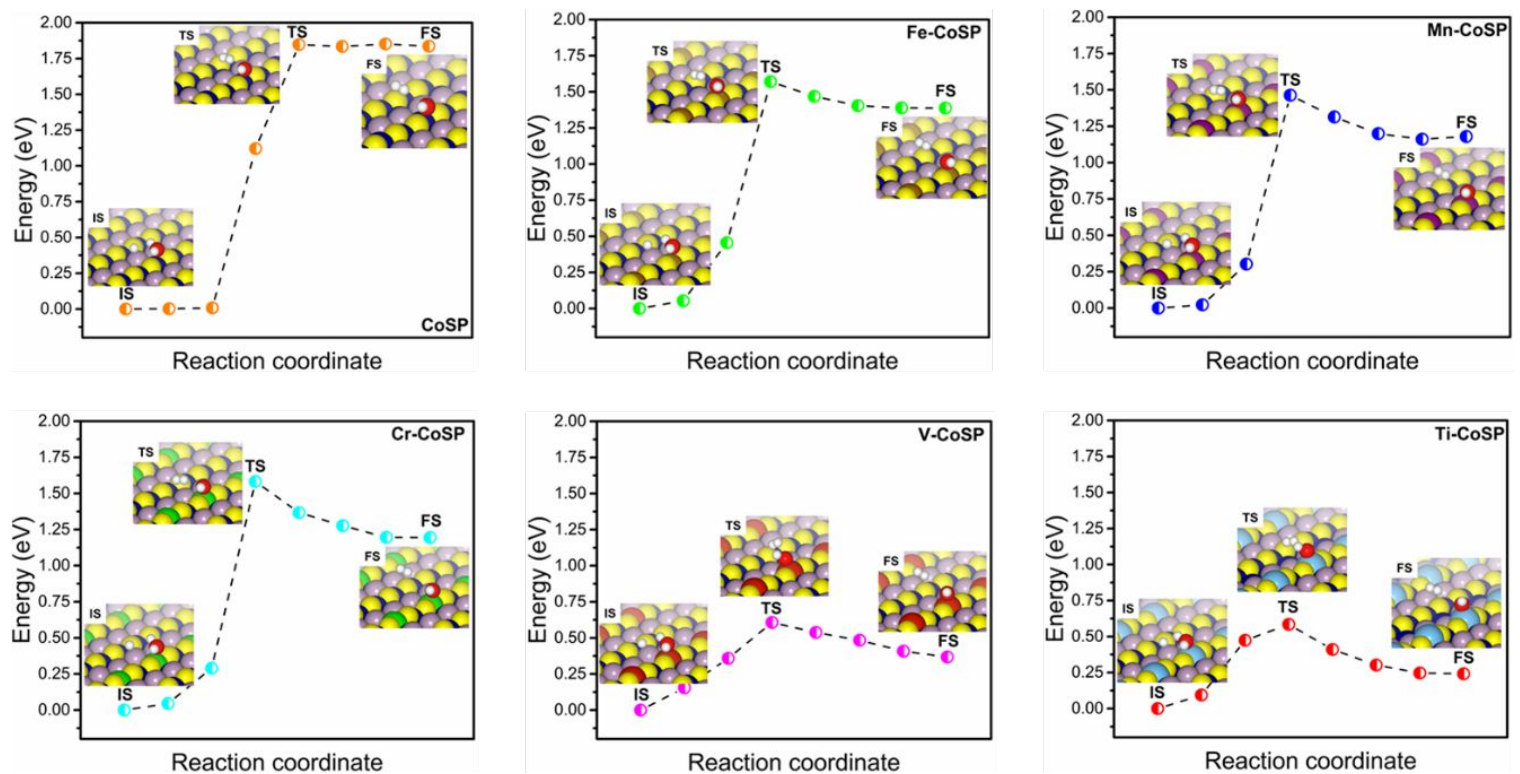

Figure S5. Determined reaction pathways of the second step via Heyrovsky's reaction. 
(a)

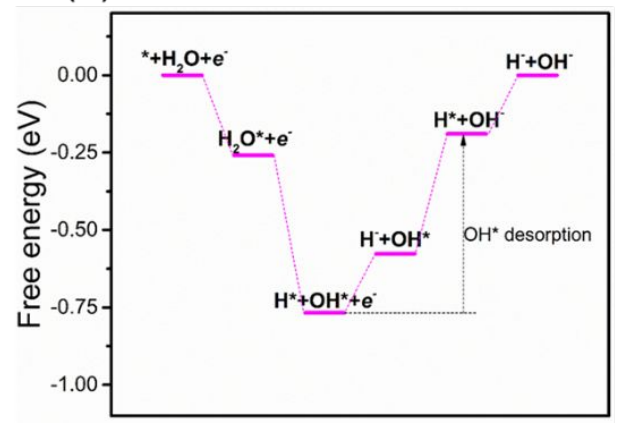

(c)

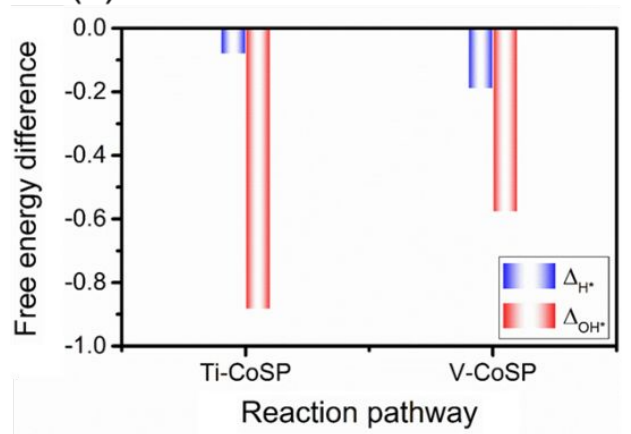

(b)

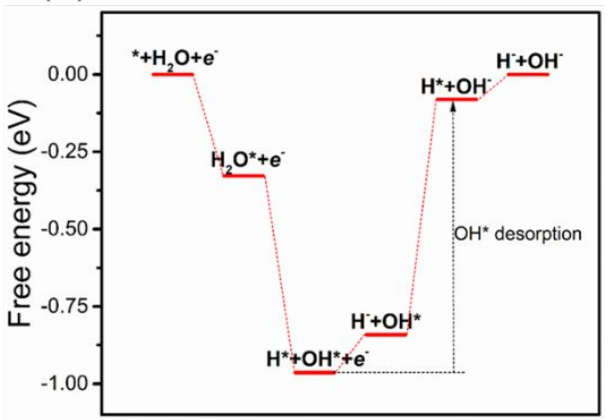

Reaction Pathway

Figure S6. Gibbs free energy diagrams of HER in alkaline condition (a) V-CoSP, (b) Ti-CoSP, and (c) free energy changes of the $\mathrm{H}^{*}$ and $\mathrm{OH}^{*}$ desorption step on V-CoSP and Ti-CoSP. 
(a)

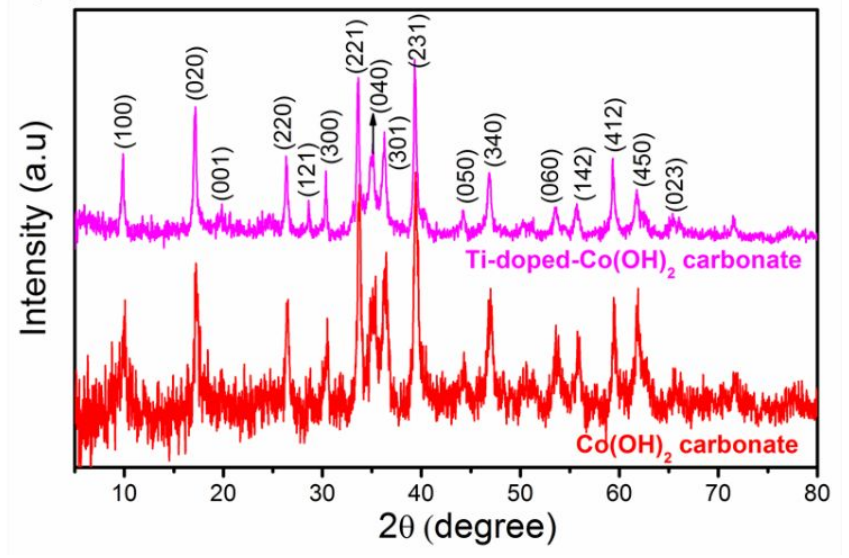

(b)

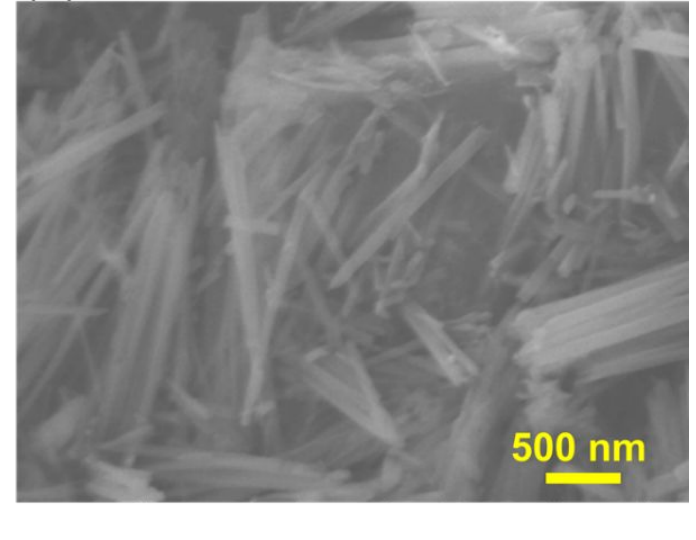

Figure S7. (a) XRD pattern of the $\mathrm{Co}(\mathrm{OH})_{2}$ and Ti-doped-Co(OH) $)_{2}$ carbonate and (b) fieldemission scanning electron microscopy (FESEM) image of Ti-doped-Co(OH $)_{2}$ carbonate. 
(a)

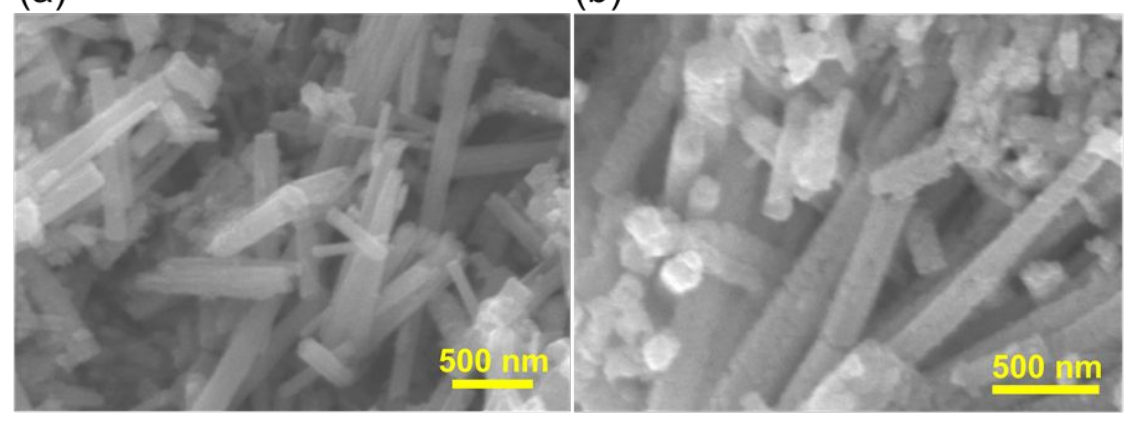

(c)

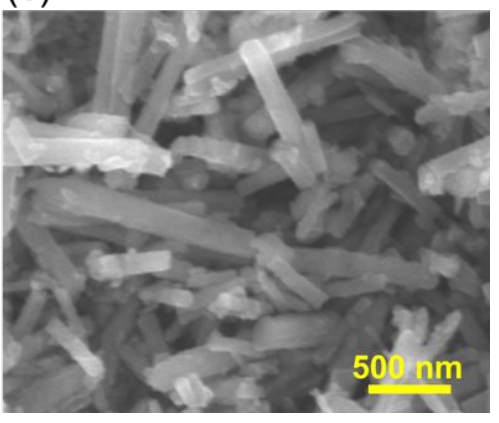

Figure S8. (a), (b) and (c) FESEM images of $\mathrm{CoS}_{2}, \mathrm{Co}_{0.97} \mathrm{Ti}_{0.03} \mathrm{~S}_{2}$ and CoSP, respectively. 
Table S3: Atomic \% of different elements and the molar ratio of S/P obtained from EDAX, averaged over multiple locations.

\begin{tabular}{cccccccc}
\hline Sample & $\begin{array}{c}\text { Co } \\
\text { (Atomic \%) }\end{array}$ & $\begin{array}{c}\text { Ti } \\
\text { (Atomic \%) }\end{array}$ & $\begin{array}{c}\text { S } \\
\text { (Atomic \%) }\end{array}$ & $\begin{array}{c}\text { P } \\
\text { (Atomic \%) }\end{array}$ & Expected & Observed \\
\hline $\mathrm{CoS}_{2}$ & 35.5 & & 64.5 & & & \\
$\mathrm{CoSP}$ & 36.94 & & 32.8 & 30.26 & $1: 1$ & $1.08: 1$ \\
$\mathrm{Co}_{0.97} \mathrm{Ti}_{0.03} \mathrm{~S}_{2}$ & 33.04 & 2.87 & 64.09 & & & \\
$\mathrm{Co}_{0.97} \mathrm{Ti}_{0.03} \mathrm{SP}$ & 32.15 & 3.23 & 33.65 & 30.97 & $1: 1$ & $1.09: 1$ \\
\hline
\end{tabular}


(a)

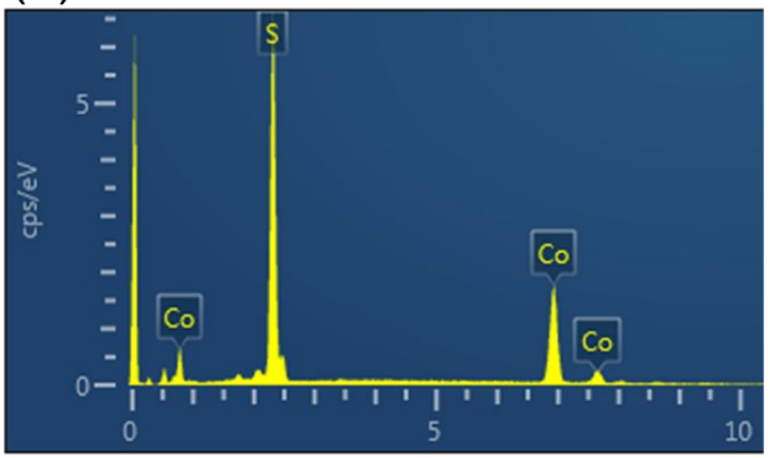

(c)

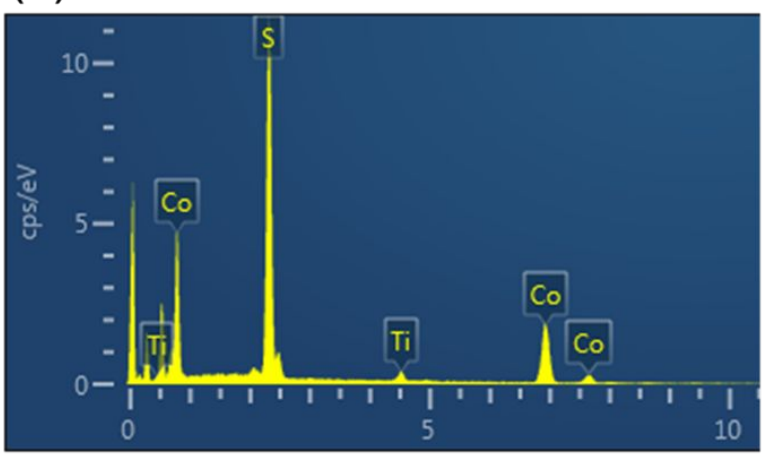

(b)

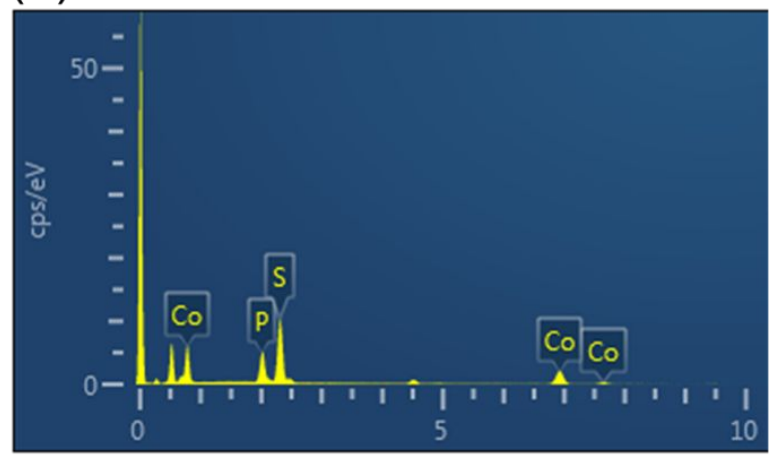

(d)

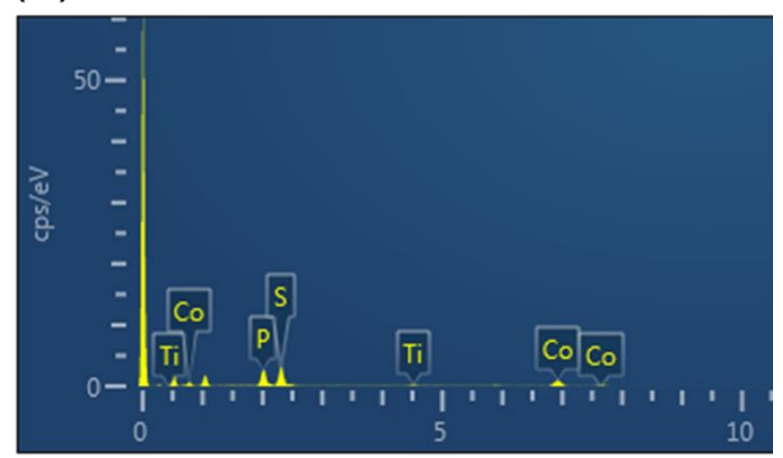

Figure S9. (a), (b), (c) and (d) EDS pattern of $\mathrm{CoS}_{2}, \mathrm{Co}_{0.97} \mathrm{Ti}_{0.03} \mathrm{~S}_{2}, \mathrm{CoSP}$ and $\mathrm{Co}_{0.97} \mathrm{Ti}_{0.03} \mathrm{SP}$, respectively. 


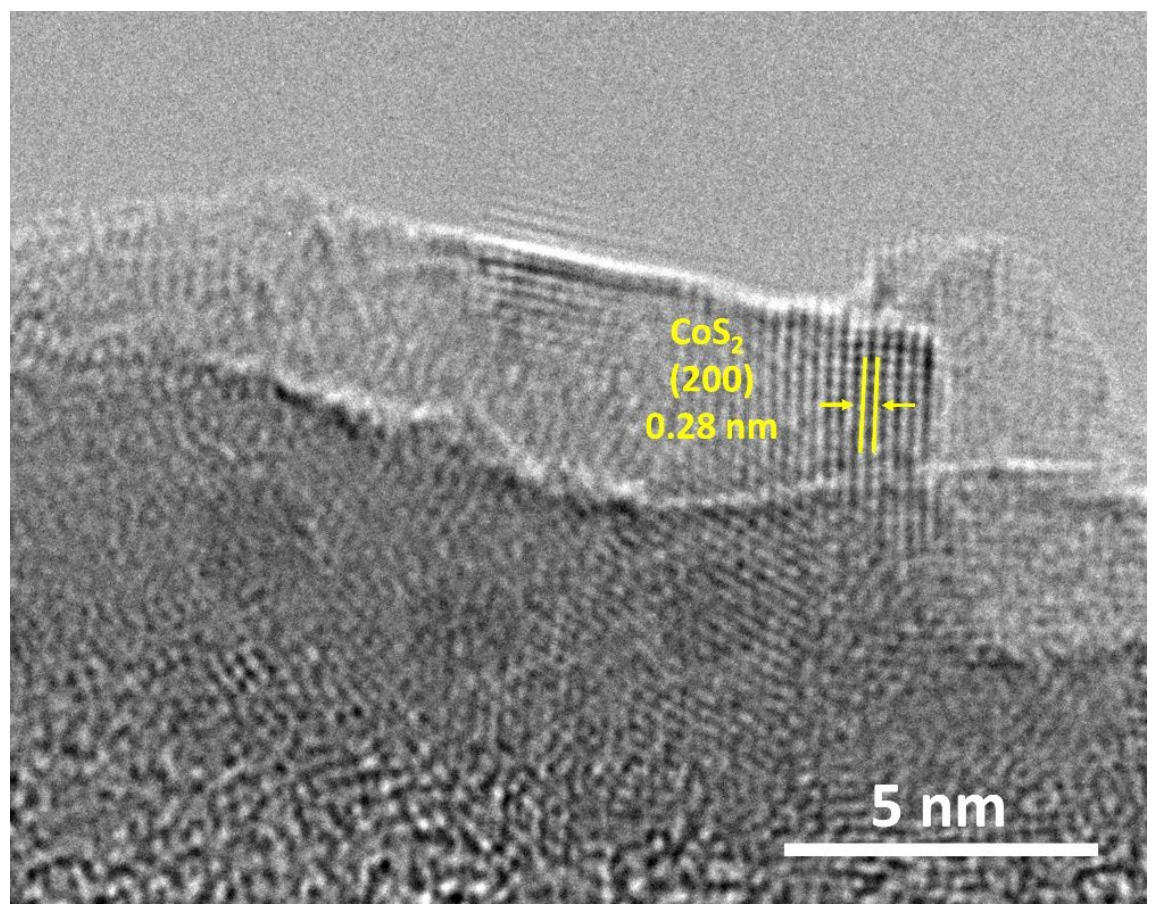

Figure S10. HRTEM images of the particles attached to the edges of the $\mathrm{Co}_{0.97} \mathrm{Ti}_{0.03} \mathrm{SP}$ nanorods. 


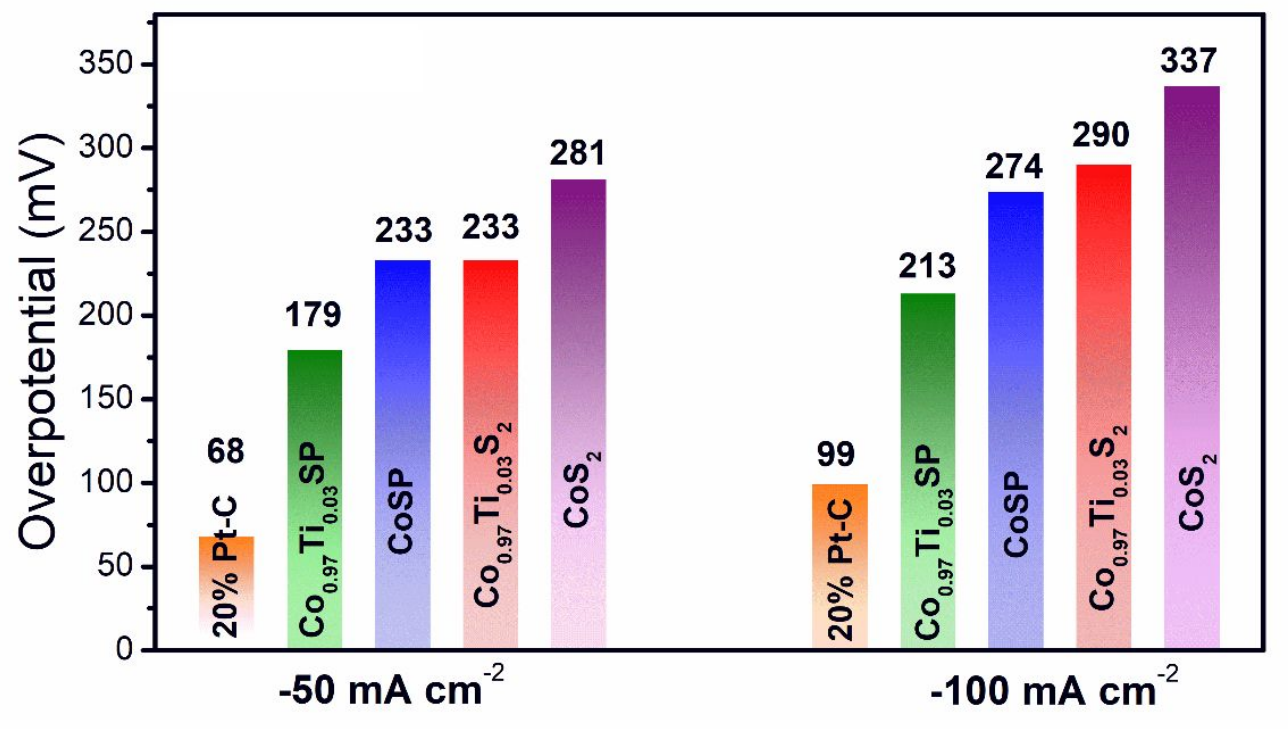

Figure S11. The overpotentials required to reach a high current density of -50 and $-100 \mathrm{~mA} \mathrm{~cm}{ }^{-2}$ for HER in acidic media. 
Table S4. Comparison table for the HER performance of catalyst in this work with other reported electrocatalysts in acidic medium.

\begin{tabular}{|c|c|c|c|}
\hline Catalyst & $\begin{array}{l}\text { Overpotential } \\
(\mathrm{mV}) @ \\
-10 \mathrm{~mA} \mathrm{~cm} \\
\end{array}$ & $\begin{array}{l}\text { Tafel slope } \\
\left(\mathrm{mV} \text { dec }^{-1}\right)\end{array}$ & References \\
\hline $\mathrm{Co}_{0.97} \mathrm{Ti}_{0.03} \mathrm{SP}$ & 44 & 51 & This work \\
\hline $\mathrm{CoPS} / \mathrm{CF}$ & 48 & 56 & [7] \\
\hline $\mathrm{Co}_{0.97} \mathrm{~V}_{0.03} \mathrm{SP}$ & 55 & 50 & {$[8]$} \\
\hline $\mathrm{Fe}_{0.9} \mathrm{Co}_{0.1} \mathrm{~S}_{2} / \mathrm{CNT}$ & 105 & 46 & {$[13]$} \\
\hline $\mathrm{CoS} \mid \mathrm{P} / \mathrm{CNT}$ & 48 & 55 & {$[32]$} \\
\hline $\mathrm{Fe} / \mathrm{P}-\mathrm{CoS}_{2}$ & 80 & 56 & {$[34]$} \\
\hline Co-Ni-S-P/Graphene & $\begin{array}{c}117(1 \mathrm{M} \\
\mathrm{KOH})\end{array}$ & $\begin{array}{c}85(1 \mathrm{M} \\
\mathrm{KOH})\end{array}$ & {$[1]^{*}$} \\
\hline $\mathrm{CoS}_{2} @ \mathrm{MoS}_{2} / \mathrm{RGO}$ & 98 & 37.8 & {$[2]^{*}$} \\
\hline $\mathrm{CoS}_{2} @ \mathrm{WS}_{2} / \mathrm{CC}$ & 97.2 & 66 & {$[3]^{*}$} \\
\hline $\mathrm{CoS}_{2}$ nanopyramid array & 70 & 64.5 & {$[4]^{*}$} \\
\hline $\mathrm{Fe}_{0.54} \mathrm{Co}_{0.46} \mathrm{~S}_{0.92} / \mathrm{CNTs} / \mathrm{CC}$ & 70 & 64 & {$[5]^{*}$} \\
\hline $\mathrm{P} / \mathrm{Co}-\mathrm{FeS}_{2} / \mathrm{CFP}$ & 63 & 51 & {$[6]^{*}$} \\
\hline Mn-dope CoP/Ti & 49 & 32 & {$[7]^{*}$} \\
\hline
\end{tabular}




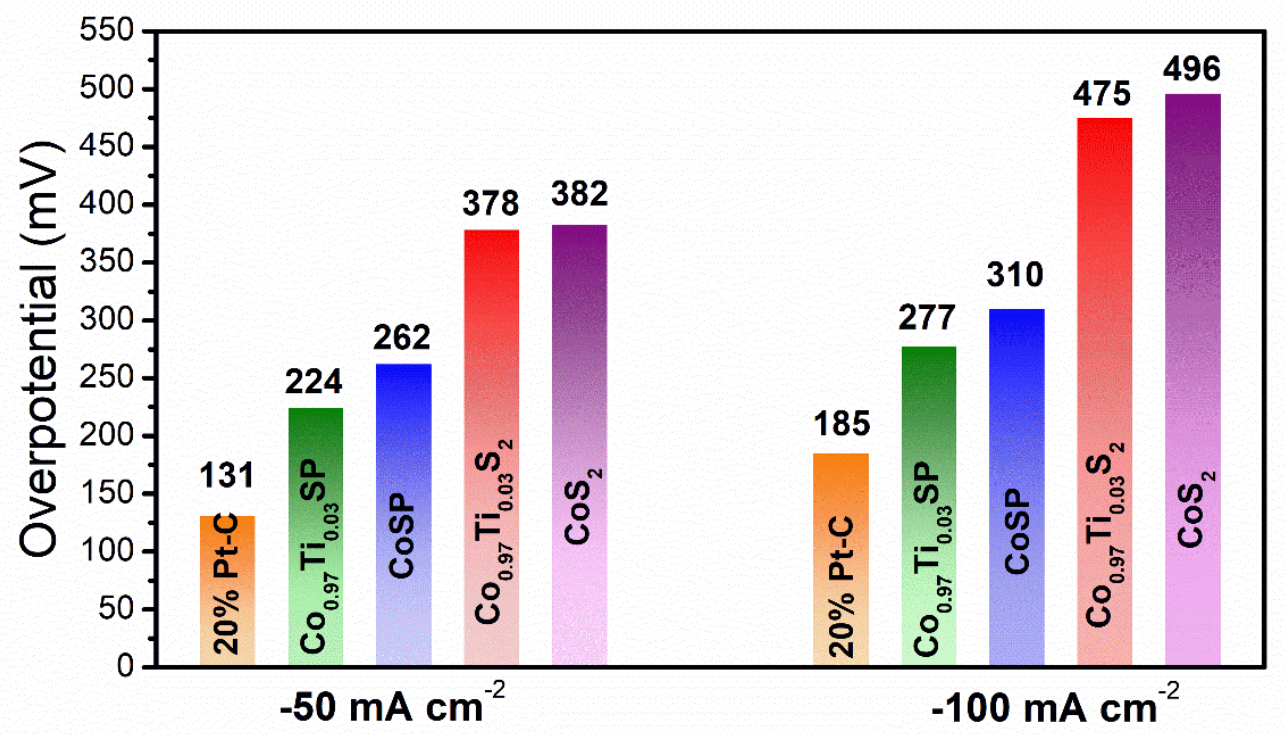

Figure S12. The overpotentials required to reach a high current density of -50 and $-100 \mathrm{~mA} \mathrm{~cm}{ }^{-2}$ for HER in alkaline media. 
(a)

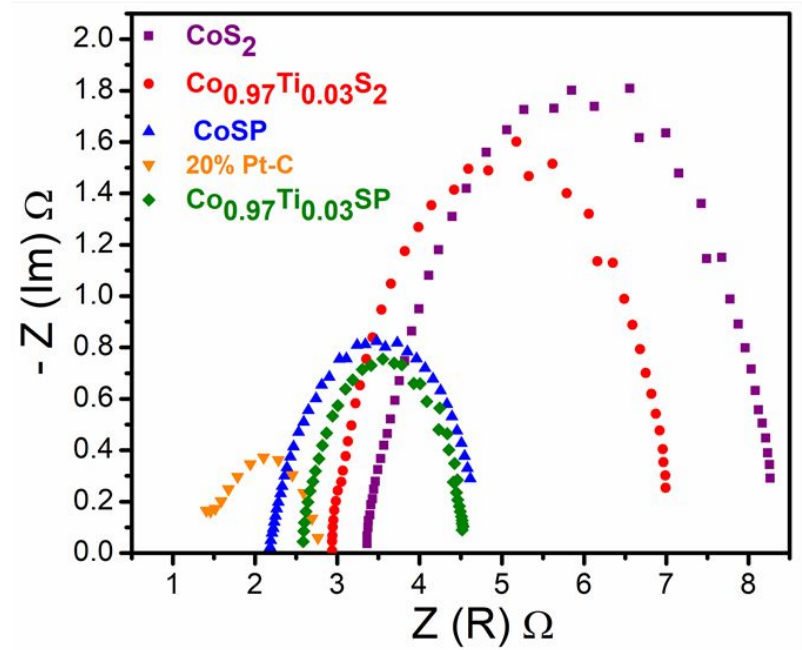

(b)

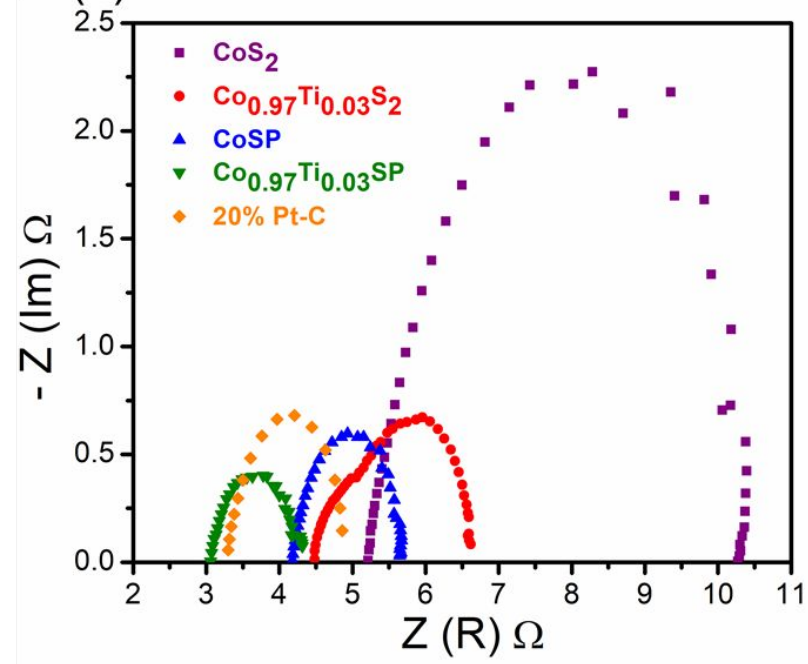

Figure S13. (a) and (b) Nyquist plots obtained by EIS at (a) $290 \mathrm{mV}$ overpotential in acid and (b) $464 \mathrm{mV}$ overpotential in alkaline medium (iR uncorrected). 
(a)
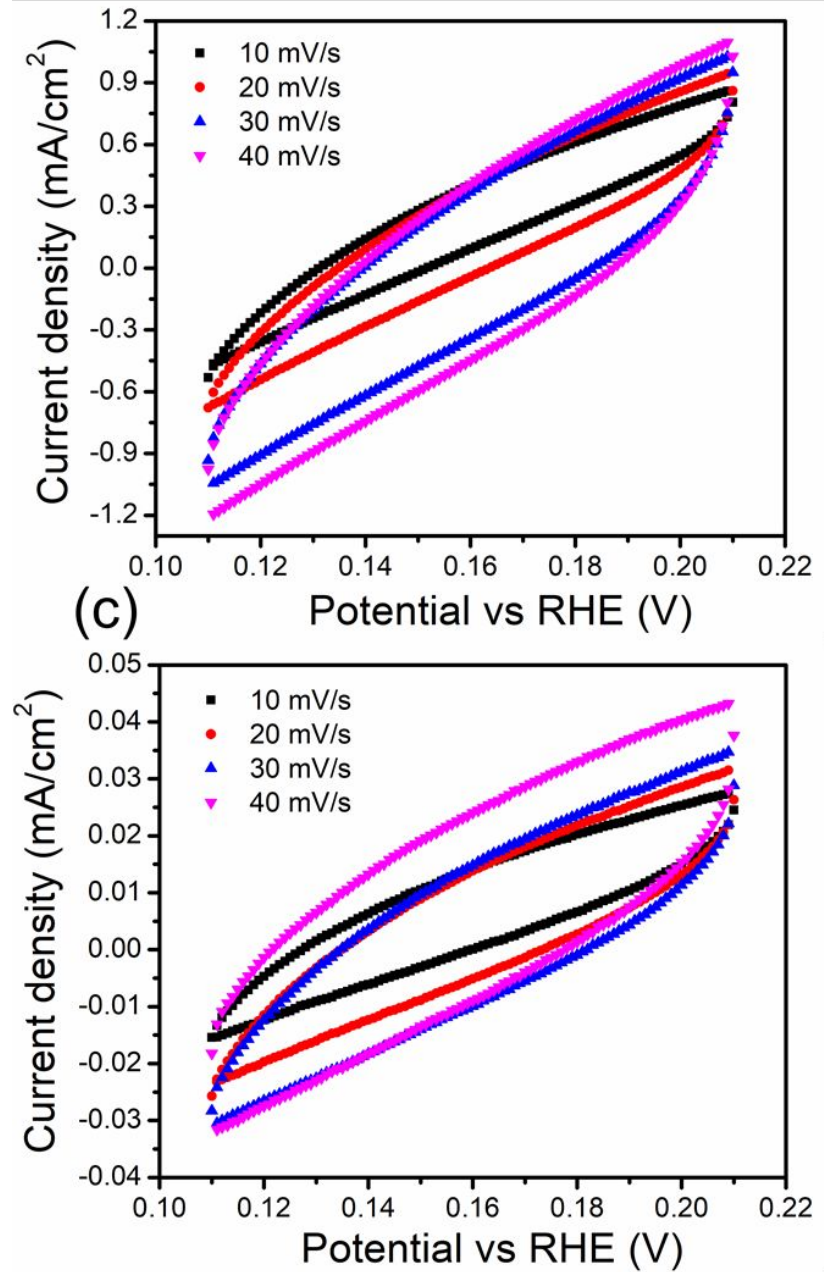

(b)
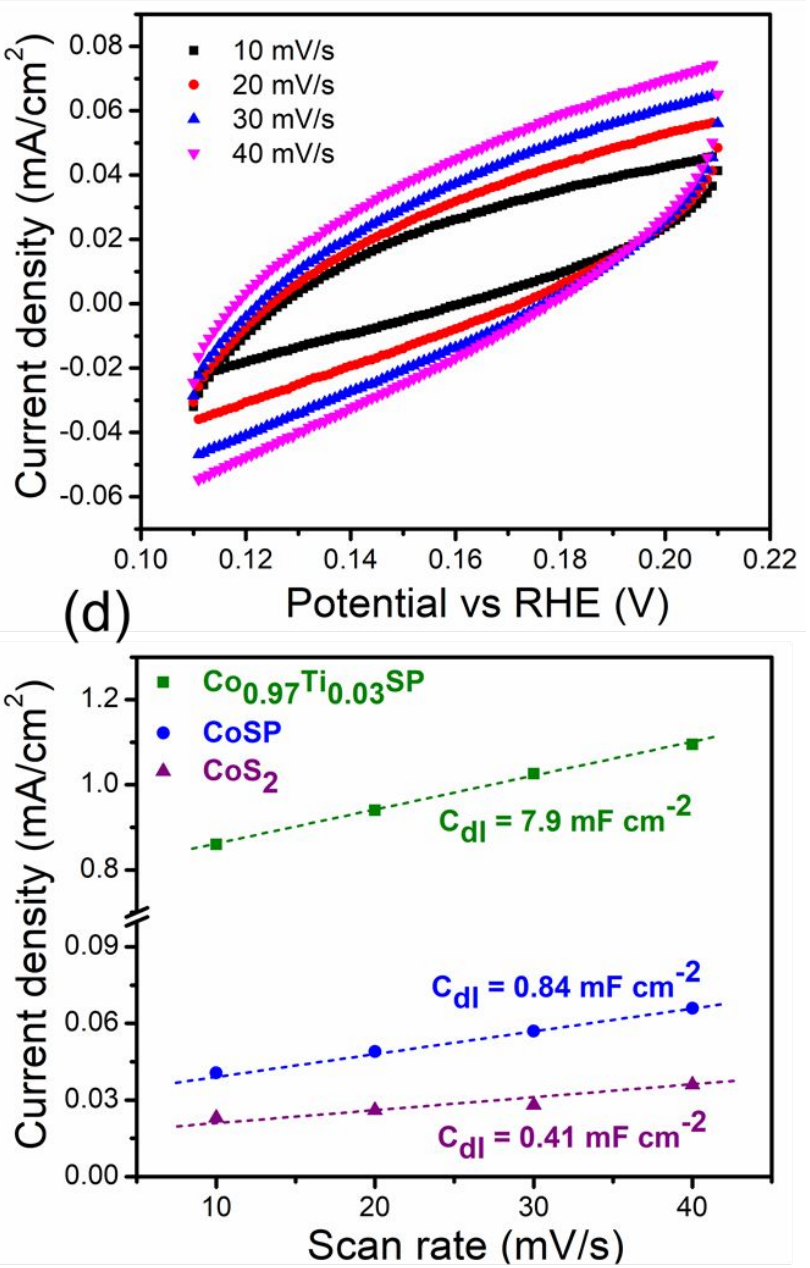

Figure S14. (a), (b) and (c) CV plots of $\mathrm{Co}_{0.97} \mathrm{Ti}_{0.03} \mathrm{SP}, \mathrm{CoSP}$ and $\mathrm{CoS}_{2}$, respectively, at different scan rates. d Corresponding current density (recorded at a fixed potential) as a function of scan rate for the extraction of the double-layer capacitance $\left(\mathrm{C}_{\mathrm{dl}}\right)$.

(a)

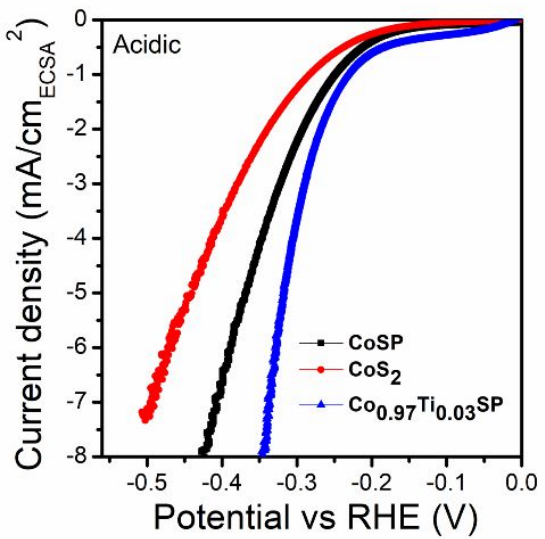

(b)

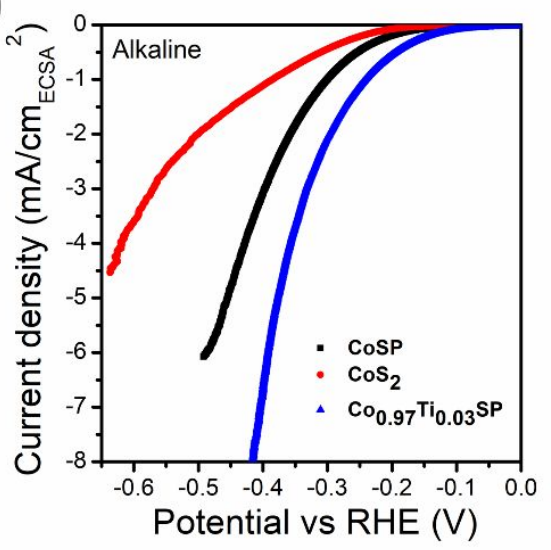


Figure S15. Normalization of HER activity with respect to their corresponding ECSA in acidic (a) and alkaline (b) media. 


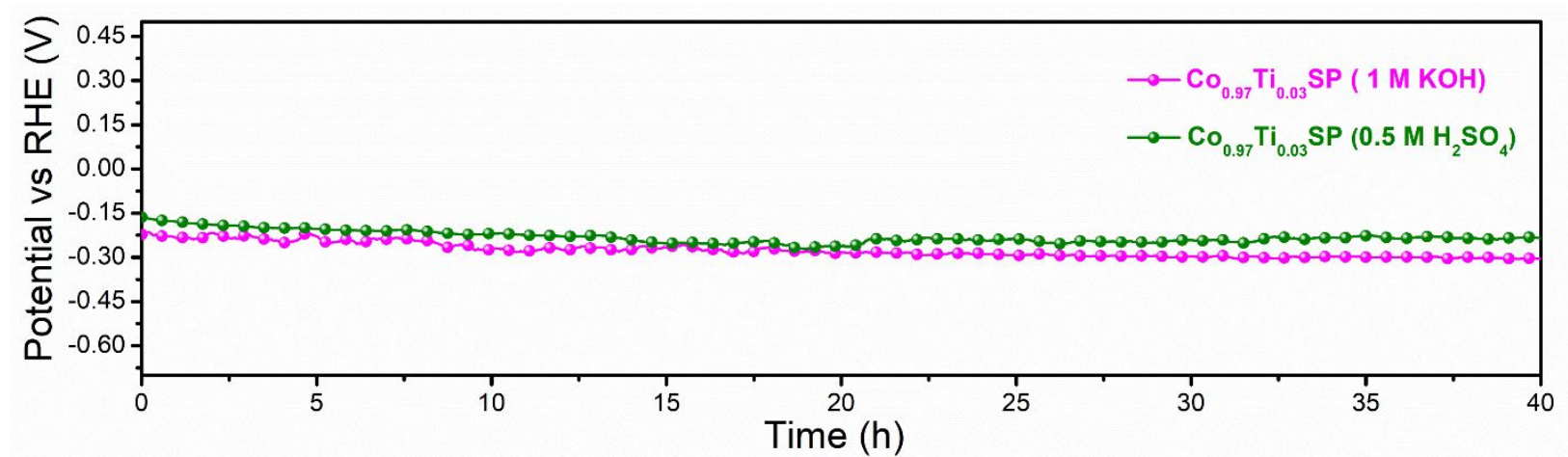

Figure S16. Long-term chronopotentiometric stability test for $\mathrm{Co}_{0.97} \mathrm{Ti}_{0.03} \mathrm{SP}$ in $0.5 \mathrm{M} \mathrm{H}_{2} \mathrm{SO}_{4}$ and $1 \mathrm{M} \mathrm{KOH}$ at a current density of $-50 \mathrm{~mA} \mathrm{~cm}^{-2}$. 
(b)

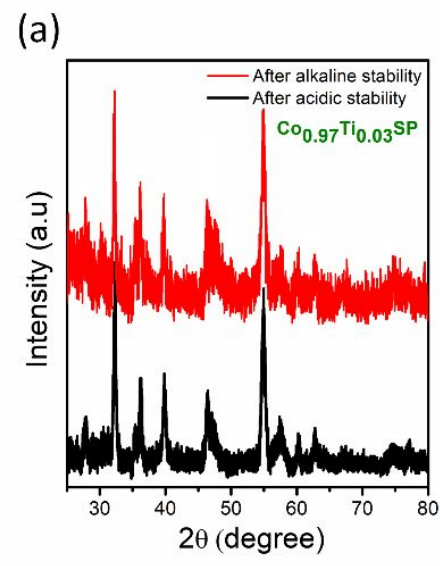

(e)
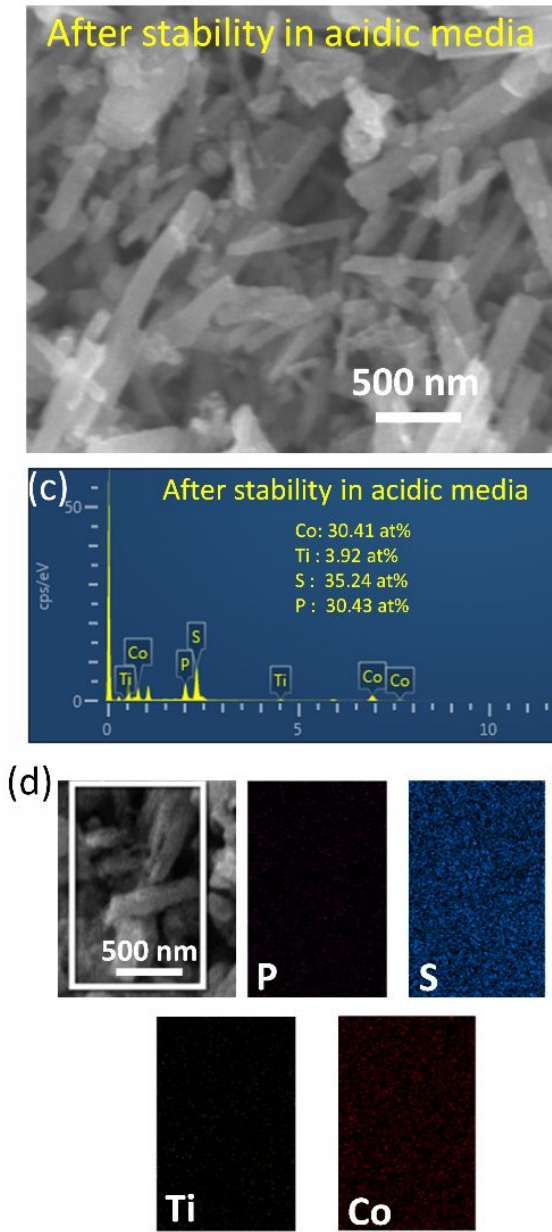
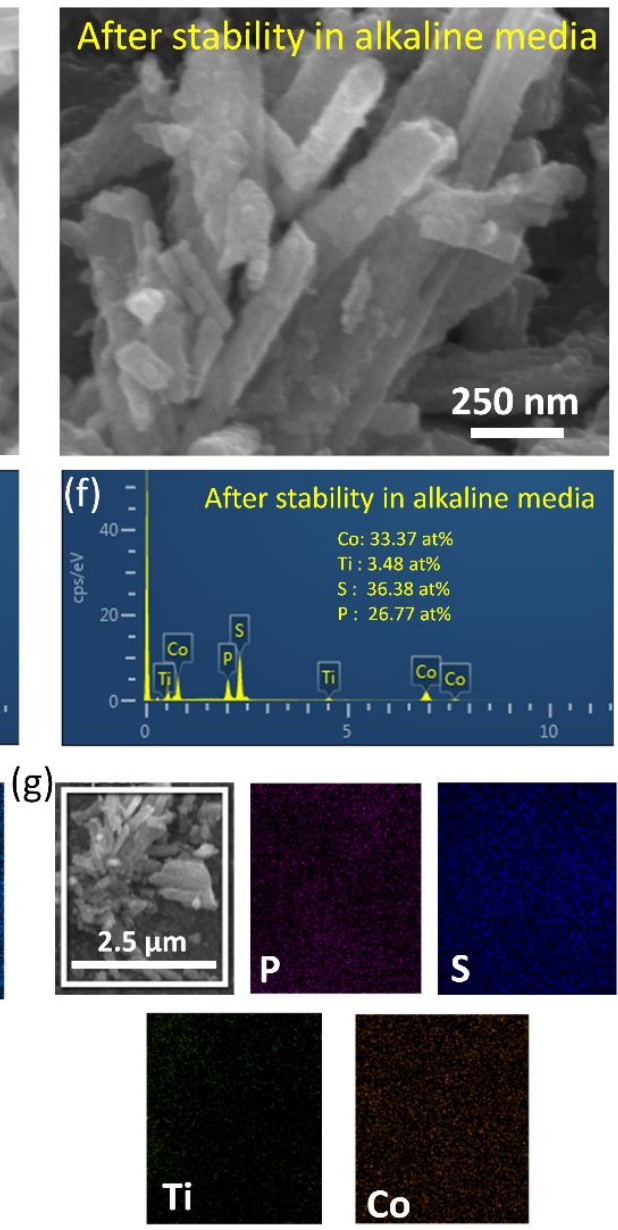

Figure S17. Characterization of the $\mathrm{Co}_{0.97} \mathrm{Ti}_{0.03} \mathrm{SP}$ catalyst after chronopotentiometric stability tests at $-100 \mathrm{mAcm}^{-2}$. (a) PXRD patterns after the stability tests in acidic and alkaline media. FESEM images, EDS spectra, and EDS mapping after the stability test in (b, c, and d) acidic and (e, f, and g) alkaline media. 
(a)

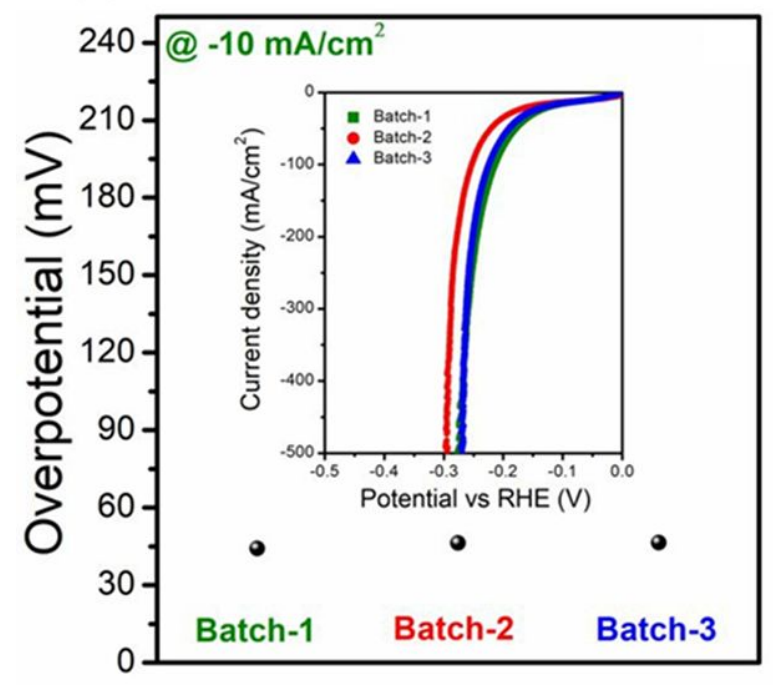

(b)

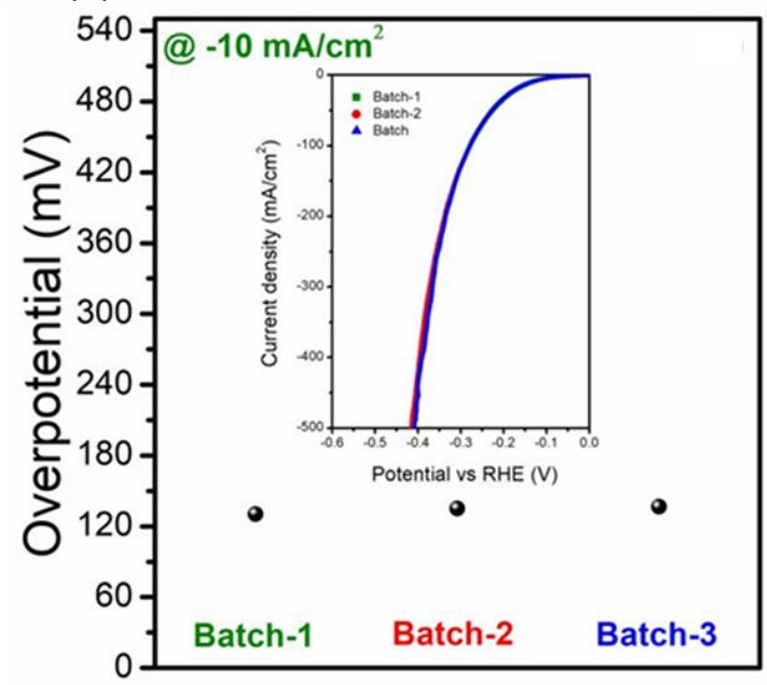

Figure S18. Reproducibility test of $\mathrm{Co}_{0.97} \mathrm{Ti}_{0.03} \mathrm{SP}$ for the HER in a $0.5 \mathrm{M} \mathrm{H}_{2} \mathrm{SO}_{4}$ and b $1 \mathrm{M}$ $\mathrm{KOH}$. 


\section{Supplemental References}

(1) Song, H. J.; Yoon, H.; Ju, B.; Lee, G. H.; Kim, D. W. 3D Architectures of Quaternary Co-NiS-P/Graphene Hybrids as Highly Active and Stable Bifunctional Electrocatalysts for Overall Water Splitting. Adv. Energy Mater. 2018, 8, 1802319.

(2) Guo, Y. X.; Gan, L. F.; Shang, C. S.; Wang, E. K.; Wang, J. A Cake-Style $\mathrm{CoS}_{2} @ \mathrm{MoS}_{2} / \mathrm{RGO}$ Hybrid Catalyst for Efficient Hydrogen Evolution. Adv. Funct. Mater. 2017, 27, 1602699.

(3) Zhou, X.; Yang, X.; Li, H.; Hedhili, M. N.; Huang, K. W.; Li, L. J.; Zhang, W. Symmetric synergy of hybrid CoS2-WS2 electrocatalysts for the hydrogen evolution reaction. J. Mater. Chem. A. 2017, 5, 15552-15558.

(4) Zhang, H.; Li, Y.; Zhang, G.; Xu, T.; Wan, P.; Sun, X. A metallic CoS2 nanopyramid array grown on 3D carbon fiber paper as an excellent electrocatalyst for hydrogen evolution. J. Mater. Chem. A. 2015, 3, 6306-6310.

(5) Xiong, W.; Guo, Z.; Li, H.; Zhao, R.; Wang, X. Rational Bottom-Up Engineering of Electrocatalysts by Atomic Layer Deposition: A Case Study of FexCo1-xSy -Based Catalysts for Electrochemical Hydrogen Evolution. ACS Energy Lett. 2017, 2, 2778-2785.

(6) Kuo, T. R.; Chen, W. T.; Liao, H. J.; Yang, Y. H.; Yen, H. C.; Liao, T. W.; Wen, C. Y.; Lee, Y. C.; Chen, C. C.; Wang, D. Y. Improving hydrogen evolution activity of earth abundant cobaltdoped iron pyrite catalysts by surface modification with phosphide. Small 2017, 13, 1603356.

(7) Liu, T.; Ma, X.; Liu, D.; Hao, S.; Du, G.; Ma, Y.; Asiri, A. M.; Sun, X.; Chen, L. Mn Doping of CoP Nanosheets Array: An Efficient Electrocatalyst for Hydrogen Evolution Reaction with Enhanced Activity at All pH Values. ACS Catal. 2017, 7, 98-102. 